\title{
The Effect of Impure Tetanus Toxin on the Frequency of Miniature End-Plate Potentials
}

\author{
BY G. A. FEIGEN AND NANCY S. PETERSON \\ Department of Physiology, Stanford University, Palo Alto, California, U.S.A. \\ W. W. HOFMANN AND G. H. GENTHER \\ Division of Neurology, U.S. Veterans Hospital, Palo Alto, California, U.S.A. \\ AND W. E. VAN HEYNINGEN \\ Sir William Dunn School of Pathology, University of Oxford
}

(Received 10 July 1963)

\section{SUMMARY}

A partially purified preparation of tetanus toxin raised the frequency of the random appearance of miniature end-plate potentials in the isolated hemithorax of the mouse. The ratio of the peripheral to the central activity was increased by removing the greater part of the centrally acting tetanospasmin by specifically adsorbing the tetanospasmin out on protagon. The activation energy of the peripheral effect was $7 \mathrm{kcal}$. higher in the presence of toxin than in its absence. The peripheral effect can be neutralized with antitoxin.

\section{INTRODUCTION}

During the past year sufficient evidence has accumulated as the result of our joint studies to indicate that a substance present in a partially purified preparation of tetanus toxin has a direct effect on peripheral neuromuscular structures. This effect is recognized by an increase in the frequency of random discharge of miniature endplate potentials (MEPP) as recorded intracellularly with micro-electrodes inserted in the intercostal muscles of the mouse. The specific fixation of the centrally active component (tetanospasmin) of tetanus toxin preparations (van Heyningen, $1959 b, c$; van Heyningen \& Miller, 1961) provided a means of assessing whether or not the wellknown central and the presently observed peripheral actions of tetanus toxin preparations are due to the same entity.

\section{METHODS}

Toxin preparations. Two partially purified preparations of tetanus toxin were obtained from Dr R. O. Thomson of the Wellcome Research Laboratories, Beckenham. Preparation TD 464 D contained $2 \times 10^{7}$ mouse LD 50/mg. It consisted of 40 \% protein and $60 \%$ salt; $75 \%$ of the protein was the centrally acting tetanospasmin. Preparation TD 594B contained $4 \times 10^{6}$ mouse LD50/mg. It consisted entirely of protein of which $6 \%$ was tetanospasmin. For physiological testing these preparations, and further preparations derived from them, were dissolved in $0 \cdot 15 \mathrm{M}$-phosphate buffer $(\mathrm{pH} 7 \cdot 0)$ containing $0 \cdot 1 \%(\mathrm{w} / \mathrm{v})$ gelatin. Stock solutions 
containing $10^{6} \mathrm{LD} 50 / \mathrm{ml}$. were diluted to provide the proper concentration for testing and dispensed in 3 to $5 \mathrm{ml}$. volumes in $5 \mathrm{ml}$. rubber-capped bottles and stored at $-20^{\circ}$ until needed. Preliminary experiments showed that these preparations were stable for at least 7 days. Results obtained with materials stored for longer periods were often erratic, and therefore samples were arbitrarily discarded after 4 days of storage. Tetanus antitoxin (1800 i.u./ml., pepsin-refined horse serum) was kindly provided by the Wellcome Research Laboratories.

Protagon. This is a water-insoluble preparation of crude sphingolipids containing 2-3\% ganglioside. It was prepared by the method of van Heyningen (1959a).

Biological assays. LD50 determinations were made by injecting serial two-fold dilutions of toxin intramuscularly into mice, two mice being used per dilution (see van Heyningen, 1959a). For electrophysiological assays intercostal preparations from male Swiss-Webster mice, averaging $20 \mathrm{~g}$. in weight, were used. Each animal was killed by a blow to the base of the skull; the thoracic cage was quickly presented and the entire spinal column, together with the adhering musculature, was cut away under a well gassed $\left(95 \% \mathrm{O}_{2}+5 \% \mathrm{CO}_{2}\right.$ ) physiological solution (Liley, 1956). Onehalf of the thorax was then mounted in a Perspex clamp and placed in a muscle bath (Peterson \& Feigen, 1962). Intracellular potentials were measured by means of micropipettes filled with $\mathbf{3} \mathbf{M}-\mathrm{KCl}$; these electrodes, which had a tip resistance of 1.1-11.0 M $\Omega$, were connected by an $\mathrm{Ag}-\mathrm{AgCl}$ bridge to the input of a cathode follower circuit (Peterson \& Feigen, 1962) and were displayed on a Tektronix 502 oscilloscope (Tektronix, Incorporated, P.O. Box 831, Portland 7, Oregon, U.S.A.), and photographed with a Grass oscilloscopic camera (Grass Instrument Company, 101 Old Colony Avenue, Quincy, Massachusetts, U.S.A.). Potentials were recorded from at least twelve cells before and after the introduction of a test solution with a $1 \mathrm{ml}$. syringe. A period of $15 \mathrm{sec}$. was allowed to elapse from the time that a cell was impaled until recording was begun; after that, records of cellular activity were taken for at least $10 \mathrm{sec}$. Cells having resting potentials of less than $60 \mathrm{mV}$. were not included. Potentials were considered acceptable only if the frequency remained stable and the amplitude averaged at least $250 \mu \mathrm{V}$. The amplitude was found to vary with the quality of the seal around the tip, its proximity to the myoneural junction, and with the cell size. The frequency rather than amplitude was considered the significant parameter in these experiments.

\section{RESULTS}

\section{Adsorption of tetanospasmin from toxin preparations}

For the specific fixation of tetanospasmin it is convenient to use water-insoluble protagon which consists of a complex of water-soluble ganglioside and various water-insoluble sphingolipids. The protagon was brought into stable suspension in water (330 mg. protein $/ \mathrm{ml}$.) with gentle heating. Toxin preparation TD594B was repeatedly treated with protagon suspension to remove tetanospasmin. This treatment consisted in adding $5 \mathrm{ml}$. of protagon suspension to $20 \mathrm{ml}$. of toxin solution $(12.5 \mathrm{mg} . / \mathrm{ml}$. water), centrifuging at $20,000 \mathrm{rev} . / \mathrm{min}$. for $20 \mathrm{~min}$. in the Spinco Model $\mathbf{L}$ preparative ultracentrifuge, discarding the residue and repeating the adsorption on the supernatant. After six such treatments only $1.25 \%$ of the tetanospasmin remained. The supernatant was dialysed and freeze-dried. The dried 
product will now be referred to as the 'non-spasmogenic preparation' (NSP). Tests in the analytical ultra-centrifuge (van Heyningen \& Miller, 1961) showed that no measurable amount of this material is fixed by ganglioside.

\section{Electrophysiology}

Standardization: consistency of measurements. In the section on Methods it was stated that the frequency rather than amplitude of miniature end-plate potentials appeared to be the more reliable variable for the assessment of the electrophysiological activity of the preparations. This decision was based on data which were obtained from control studies on sixty-one mice and which include observations made, in most cases, on both hemithoracic sections. The average frequency observed for 100 hemithoraces at $35 \cdot 1 \pm 0 \cdot 1^{\circ}$ was $5 \cdot 35 \pm 0 \cdot 29 \mathrm{sec} .^{-1}$, and the average amplitude was $402 \pm 13 \mu \mathrm{V}$. The question arose next whether the variation between the hemithoraces of one mouse was significantly less than that among the mice taken at random. Sufficient data were at hand in the sixty-one mice to permit a statistical analysis to be made of the consistency between the first and the second hemithoraces. In forty duplicate tests the mean frequency of the first hemithorax was 5.27 sec. $^{-1}$, and that of the second hemithorax was $4.73 \mathrm{sec}^{-1}$. The slope of the regression line, $b$, was 0.29 and its standard error was $0 \cdot 14$. The ratio of the slope to its standard error, $t$, was 2.08 which was significant at the $5 \%$ confidence level. The correlation, $r$, between the two halves was $0 \cdot 33$. A similar analysis of the amplitude data, on thirty-six duplicate cases, gave the following statistical information: the mean amplitudes were 410 and $443 \mu \mathrm{V}$. for the first and second halves, respectively; the regression coefficient of the first half on the second half was $0 \cdot 39 \pm 0 \cdot 18$, and the $t$ value of $2 \cdot 20$ was significant at the $5 \%$ level. The correlation was $0 \cdot 35$.

Since both tests showed such poor internal correlations, it was not thought advantageous to use one half of the hemithorax as a control for the second, and therefore all subsequent experiments were made with a single preparation from a given animal, using the ratio between test and control as a means of expressing the effect of the sample under test.

Standardization: $\mathrm{Ca}, \mathrm{K}$, and curare. The possibility that the increased frequency of MEPP might have come about because of the small amount of potassium present in the gelatin and from the ionic calcium in the toxin preparation itself was ruled out by direct experiment. The physiological solution, which was used in the controls as well as the experiments, contained $\mathrm{Ca}$ and $\mathrm{K}$ in concentrations of 2.0 and $5 \cdot 0 \mathrm{~mm} / \mathrm{l}$., respectively. The effect of quadrupling the Ca concentration was found, in three experiments, to double the natural MEPP frequency; the effect of raising the $\mathrm{K}$ concentration $\mathbf{2 . 5}$ times was to increase the frequency 4 - to 15 -fold. If the dried test material consisted entirely of $\mathrm{CaCl}_{2}$, the concentration of $\mathrm{Ca}$ in stock solutions (see Methods) could not be more than $0.92 \mathrm{~mm} / 1$.; since the stock solutions were finally diluted at least $1 / 68$ in the physiological solution (see below) the final concentration of $\mathrm{Ca}$ from this source could not be more than $0 \cdot 136 \mathrm{~mm} / \mathrm{l}$., i.e. less than that of the physiological solution. In the same way the $\mathbf{K}$ derived from the gelatin of the stock solution would be insignificant compared with that of the physiological solution.

Curare $\left(3.7 \times 10^{-4} \mathrm{mg} . / \mathrm{ml}\right.$. final concentration) reduced the MEPP amplitude to below noise level in both the control preparations and those in which frequency had 
been increased by the highest concentration of toxin preparations used in these experiments.

Dose-response curves. The relationship between the concentration of the active agent and the response was determined at $35^{\circ}$ for both the parent toxin preparation and the NSP over approximately the same range of concentrations. The results in Table 1 give the average control and test frequencies observed on 4-7 hemithorax preparations at each dosage-level. Control records were taken after an equilibrium period of at least $30 \mathrm{~min}$. and test measurements were made $10 \mathrm{~min}$. after the addition of $1 \mathrm{ml}$. of test solution to the bath. Control and test records were taken from muscle cells supplied by the same nerve twig and, in so far as possible, the same cells were sampled before and after the addition of test material.

\section{Table 1. Dose-response summary}

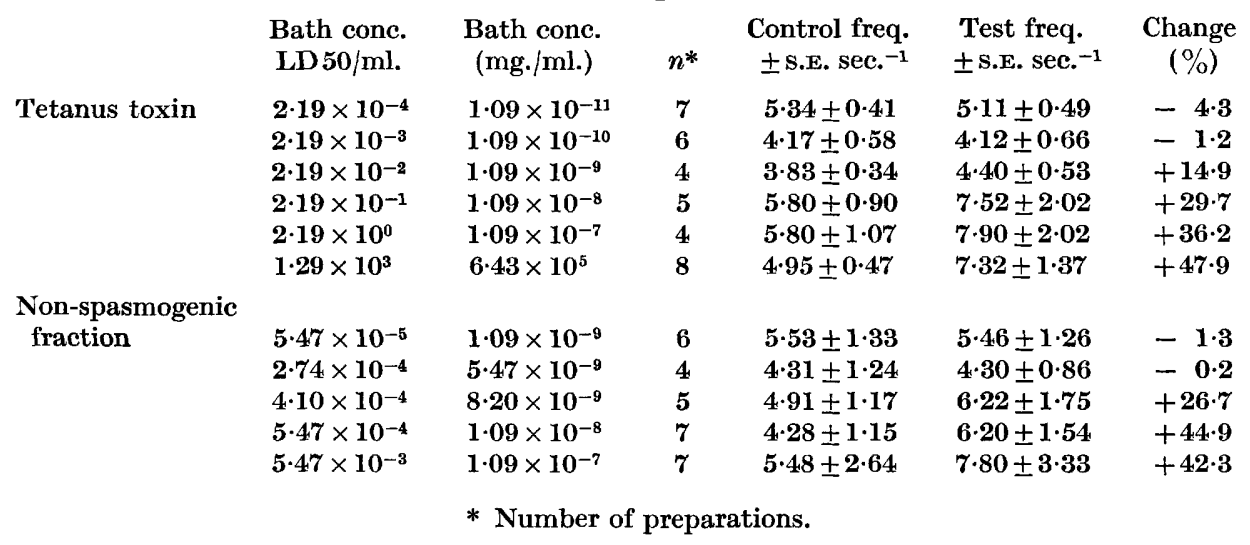

The results plotted in Fig. 1 are the ratios of the mean test/control frequencies. Figure $1 a$ shows at once that the principal distinction between the parent toxin preparation and the NSP lies not in the median effective (gram) dose, but in the heterogeneity of the sigmoid curve displayed by the parent preparation. It is evident that one of the consequences of adsorption with protagon was to increase the uniformity of the material producing the peripheral effect. The separation of the central spasmogenic effect from the peripheral effect by treatment with protagon is evident in Fig. 1 $b$, which shows the mean peripheral activity to lie at about $5 \cdot 4 \times 10^{-2} \mathrm{LD} \mathrm{50} / \mathrm{ml}$. in the case of the parent material and at $3.9 \times 10^{-4} \mathrm{LD} \mathrm{50} / \mathrm{ml}$. for that of the NSP.

The degree of purification of NSP achieved by treating the crude preparation with protagon can be estimated by comparing the MEPP 50:LD 50 ratios/mg. protein for the two preparations. By taking the calculated mid-points of the MEPP curves as effective reference values, and correcting the toxicity and the MEPP data for activity per milligram of protein, we obtain the results shown in Table 2. From this summary it is evident that the MEPP activity is concentrated in the NSP remaining after the removal of the tetanospasmin by protagon.

Effect of temperature. The effect of the parent toxin preparation on MEPP was characterized with respect to temperature. The experiments were performed essentially as described under Methods with the exception that a larger muscle bath (114 $\mathrm{ml}$.) was used to insure temperature stability. The frequency of MEPP was 

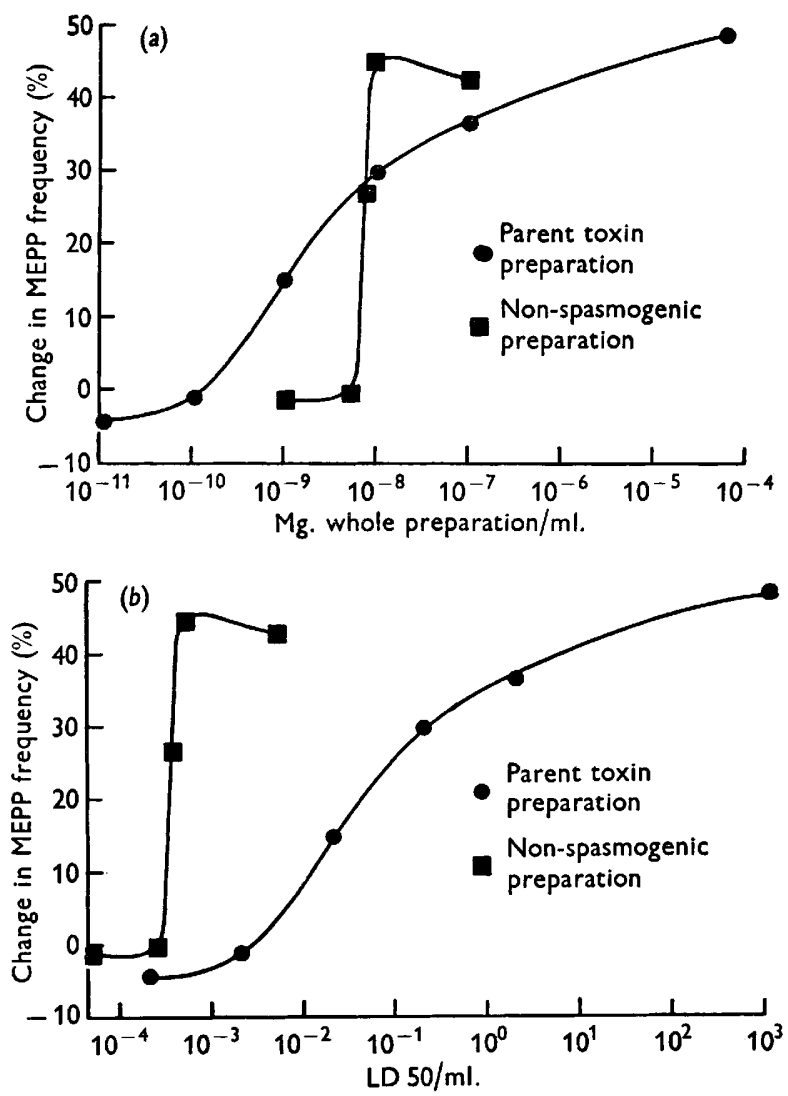

Figs. $1 a$ and $b$. Comparison of parent toxin preparation with non-spasmogenic preparation by total weight $(a)$ and by toxicity $(b)$. Percentage change in MEPP frequency from control to test is plotted as a function of the logarithm of the concentration. 0 , parent-toxin preparation; $\boldsymbol{\square}$, non-spasmogenic preparation.

Table 2. Specific central and peripheral activities of the parent toxin preparation and non-spasmogenic preparation derived from it

LD 50/mg. protein MEPP 50/mg. protein MEPP 50:LD 50

$\begin{array}{lllr}\text { Parent preparation } & 5 \times 10^{7} & 9.26 \times 10^{8} & 18.5 \\ \text { NSP } & 5 \times 10^{4} & 1.28 \times 10^{8} & 2560\end{array}$

studied at five temperatures ranging from $27 \cdot 6$ to $39 \cdot 5^{\circ}$ before and after the administration of a dose of the parent toxin preparation which provided a final concentration in the bath of $0.064 \mathrm{mg} . / \mathrm{ml}$. Six to eight hemithoraces were tested at each point in temperature, and the average values for the control and test frequencies are given in Table 3.

The uniformity of the response with respect to temperature was tested by plotting the logarithms of the average frequencies against the corresponding reciprocals of absolute temperatures. Figure 2 shows that this function is linear. The slope, hence the activation energy, of the toxin line is greater than that of the control function, and both least squares lines converge upon a common point at $27 \cdot 6^{\circ}$. A statistical 


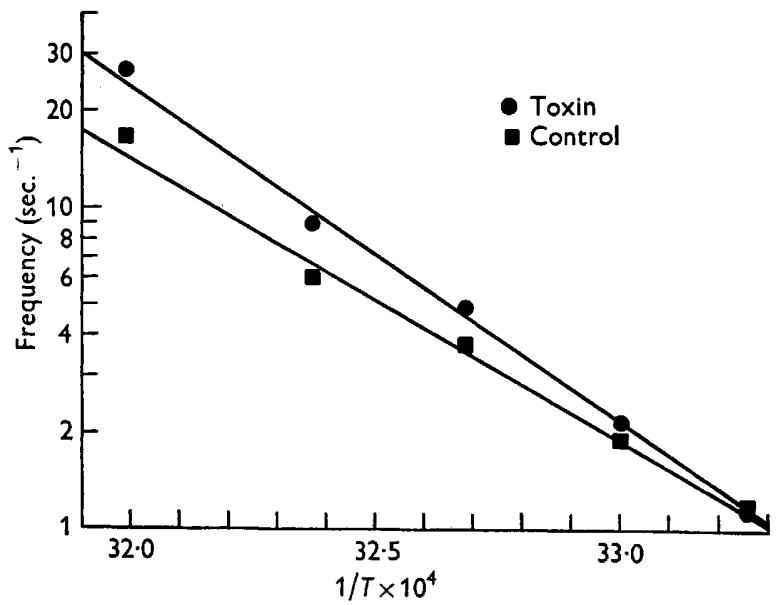

Fig. 2. Effect of temperature and tetanus toxin on the frequencies of miniature end-plate potentials. Logarithm of frequency is plotted as a function of the reciprocal of the absolute temperature. $O$, tetanus toxin; $\square$, controls.

Table 3. Effect of temperature and tetanus toxin on frequency of MEPPS

\begin{tabular}{|c|c|c|}
\hline Temp. & $\begin{array}{l}\text { Control freq. } \\
\quad\left(\text { sec. }^{-1}\right)\end{array}$ & $\begin{array}{l}\text { Test freq. } \\
\text { (sec. }^{-1} \text { ) }\end{array}$ \\
\hline $27 \cdot 55^{\circ}$ & $1 \cdot 21 \pm 0 \cdot 14$ & $1 \cdot 20 \pm 0 \cdot 10$ \\
\hline $29 \cdot 90^{\circ}$ & $1 \cdot 92 \pm 0 \cdot 14$ & $2 \cdot 13 \pm 0 \cdot 11$ \\
\hline $32 \cdot 85^{\circ}$ & $3.79 \pm 0.36$ & $4.88 \pm 0.41$ \\
\hline $38 \cdot 80^{\circ}$ & $5.95 \pm 0.47$ & $8.93 \pm 1.37$ \\
\hline $39 \cdot 50^{\circ}$ & $16 \cdot 8 \pm 2 \cdot 0$ & $26 \cdot 9 \pm 3 \cdot 2$ \\
\hline
\end{tabular}

* In the presence of $0.064 \mathrm{mg} . / \mathrm{ml}$. of tetanus toxin.

$\dagger$ Number of preparations.

analysis performed on the data showed the difference between the slopes to be significant at the $0.001 \%$ confidence level.

The activation energy was calculated by means of the Arrhenius equation,

$$
\log \frac{K_{2}}{K_{1}}=\frac{E_{a}\left(1 / T_{1}-1 / T_{2}\right)}{2 \cdot 303 R}
$$

in which $E_{a}$ is the energy of activation in calories, $R$ is the gas constant $=1.987 \mathrm{cal}$. degree $^{-1}$ mole $^{-1}$, and $K$ is the frequency of MEPP in sec. ${ }^{-1}$

Since the functions are linear and the slopes are given by

$$
\frac{-E_{a}}{2 \cdot 3 R}
$$

the activation energy may be calculated from any two coordinates taken from the regression line. Taking the values of $K$ from the line at $1 / T=32 \times 10^{-4}$ and at $33 \times 10^{-4}$, we get an activation energy of $39.9 \mathrm{kcal}$. and $47 \cdot 3 \mathrm{kcal}$. for the control and the toxin categories, respectively.

Neutralization with antitoxin. Table 4 shows that antitoxin neutralizes the stimulating effect of partially purified toxin on MEPP. 
Table 4. Effect of toxin and toxin-antitoxin on MEPP frequency

$\begin{array}{lccc} & n^{*} & \begin{array}{c}\text { Control freq. } \\ \left(\text { sec. }^{-1}\right)\end{array} & \begin{array}{c}\text { Test freq. } \\ \left(\text { sec. }^{-1}\right)\end{array} \\ \text { Toxin (TD464D) } \dagger & 6 & 10 \cdot 62 \pm 1 \cdot 15 & 13 \cdot 30 \pm 1 \cdot 44 \\ \text { Toxin-antitoxin } & 5 & 10 \cdot 97 \pm 1 \cdot 47 & 10 \cdot 28 \pm 1 \cdot 59\end{array}$

These experiments were made at $36 \cdot 9^{\circ}$

* Number of preparations.

$\dagger$ Final toxin concentration was $2 \cdot 6 \times 10^{-2} \mathrm{LD} \mathrm{50} / \mathrm{ml}$. ; final antitoxin concentration was enough to neutralize the lethal action of the toxin in mice.

\section{DISCUSSION}

We have established that one or more of the constituents of a partially purified preparation of tetanus toxin has a peripheral neuromuscular effect which can be demonstrated by the increased frequency of the random appearance of miniature end-plate potentials. More than $98 \%$ of the centrally active tetanospasmin can be removed by specific adsorption on protagon, leaving a protein preparation with a greatly increased ratio of peripheral to central activity.

As far as we are aware, the present data concerning the activation energy of MEPP are the most complete over the temperature range used, and they differ in magnitude from those given by other authors. Whereas $Q_{10}$ values from 3 to $4 \cdot 8$ have been observed in the frog (Fatt \& Katz, 1952; Takeuchi, 1958) and from 2.1 to 3.5 in mammals (Liley, 1956; Boyd \& Martin, 1956), our data give a figure of about 5 to 8 depending on the temperatures chosen (Table 3 ). The fact that an additional $7 \mathrm{kcal}$. is required for the action of toxin suggests that this process involves the breaking of a bond of moderate strength and possibly is enzymic.

These studies were made under Contract NR 225(46) between Stanford University and the Office of Naval Research and were also supported by a grant from the Santa Clara County Heart Association.

\section{REFERENCES}

Boyd, I. A. \& Martin, A. R. (1956). Spontaneous subthreshold activity at mammalian neuromuscular junctions. J. Physiol. 132, 61.

FATt, P. \& KATz, B. (1952). Spontaneous subthreshold activity at motor nerve endings. J. Physiol. 117, 109.

LiLEy, A. W. (1956). Spontaneous activity at the neuromuscular junction of the rat. J. Physiol. 132, 650.

Peterson, N. S. \& Feigen, G. A. (1962). Effect of $\left[\mathrm{NO}_{3}\right]$ on atrial action potentials and contraction as modified by [Na] and [Ca]. Amer. J. Physiol. 202, 950.

TakeUchr, N. (1958). The effect of temperature on the neuromuscular junction of the frog. Jap. J. Physiol. 8, 391.

van Heyningen, W. E. $(1959 a)$. The fixation of tetanus toxin by nervous tissue. J. gen. Microbiol. 20, 291.

van Heyningen, W. E. (1959b). Chemical assay of tetanus toxin receptor in nervous tissue. J. gen. Microbiol. 20, 301.

van Hexningen, W. E. $(1959 c)$. Tentative identification of tetanus toxin receptor in nervous tissue. J. gen. Microbiol. $20,310$.

van Heyningen, W. E. \& Mrller, P. A. (1961). The fixation of tetanus toxin by ganglioside. J. gen. Microbiol. 24, 107. 